\title{
Clinicopathological characteristics and prognosis of stage IV colorectal cancer
}

\author{
NORIKATSU MIYOSHI $^{1 *}$, MASAYUKI OHUE $^{1 *}$, TATSUSHI SHINGAI ${ }^{2}$, SHINGO NOURA $^{1}$, \\ KEIJIRO SUGIMURA ${ }^{1}$, HIROFUMI AKITA ${ }^{1}$, KUNIHITO GOTOH ${ }^{1}$, MASAAKI MOTOORI ${ }^{1}$, \\ HIDENORI TAKAHASHI $^{1}$, KENTARO KISHI ${ }^{1}$, JIRO OKAMI $^{1}$, SHIGERU MARUBASHI ${ }^{1}$, \\ YOSHIYUKI FUJIWARA ${ }^{1}$, MASAHIKO HIGASHIYAMA ${ }^{1}$ and MASAHIKO YANO ${ }^{1}$ \\ ${ }^{1}$ Department of Surgery, Osaka Medical Center for Cancer and Cardiovascular Diseases, Osaka, Osaka 537-8511; \\ ${ }^{2}$ Department of Surgery, Saiseikai Senri Hospital, Suita, Osaka 565-0862, Japan
}

Received October 6, 2014; Accepted January 28, 2015

DOI: $10.3892 / \mathrm{mco} .2015 .598$

\begin{abstract}
The aim of this study was to determine the role of curative resection in metastatic colorectal cancer (CRC) and determine the subset of patients who may benefit from concurrent curative resection of primary and metastatic lesions. A total of 103 patients diagnosed with synchronous liver and/or lung metastatic CRC at the Osaka Medical Center for Cancer and Cardiovascular Diseases between 1983 and 2010 were retrospectively investigated. All the patients underwent curative resection of the primary and metastatic lesions. The median follow-up time was 5.69 years. A total of 83 and 13 patients had only liver or lung metastasis, respectively, whereas 7 patients had synchronous liver and lung metastases. A total of 25 patients (24.2\%) had no recurrence following curative resection and 14 patients (13.5\%) received more than one re-resection for disease recurrence and survived without any further recurrence thereafter. The 5-year survival of liver or lung metastatic CRC was 43.7 or $90.0 \%$, respectively. However, the median overall survival (OS) in patients with synchronous liver and lung metastases was 20.7 months. In the univariate and multivariate analyses, tumour invasion, synchronous liver and lung metastases and time-to-recurrence after the first curative resection were significantly associated with OS and disease-free survival. In conclusion, curative resection confers longer-term survival in patients with liver or lung metastatic CRC.
\end{abstract}

Correspondence to: Dr Norikatsu Miyoshi, Department of Surgery, Osaka Medical Center for Cancer and Cardiovascular Diseases, 1-3-3 Nakamichi, Higashinari-ku, Osaka, Osaka 537-8511, Japan

E-mail: miyosi-no@mc.pref.osaka.jp

${ }^{*}$ Contributed equally

Key words: colorectal cancer, metastatic cancer, liver metastasis, lung metastasis, distant metastasis

\section{Introduction}

In developed countries, where the aging population is on the increase, cancer is a major health concern, in terms of public welfare and preventive measures, with a cancer-related to overall mortality ratio of 1:4 in the United States (1). Colorectal cancer (CRC) is one of the most common malignancies and among the leading causes of cancer-related mortality. Approximately 1 in 5 patients with CRC present with distant metastatic disease at diagnosis and the distant metastases, such as to the liver or lung, are the major cause of death. A significant proportion of patients with metastatic CRC are not curable; however, a subset of these patients with liver- and/or lung-isolated disease is potentially curable with surgery (2-4).

When treating metastatic CRC, systemic chemotherapy is the standard approach. Over the last decade, there has been significant progress in CRC treatment strategies. Compared to the era when 5-fluorouracil (5-FU) was the only efficient drug against $\mathrm{CRC}$, the median survival duration has increased over the last few years, mainly due to the availability of novel agents, such as irinotecan and oxaliplatin, along with cetuximab and bevacizumab (5-7). Although several new drugs are currently used for metastatic CRC, it is difficult to change the standard treatment with surgical resection.

The role of synchronous curative resection for CRC with lung and/or liver metastases is limited. Previous studies on these treatments were retrospective and included small sample sizes with short-term follow-up periods $(3,4)$. Therefore, it is difficult to determine the benefits of curative resection for primary and metastatic lesions concurrently. In this study, the treatment outcome of curative resection combined with standard chemotherapy was evaluated in patients with liver and/or lung metastatic CRC. Furthermore, the clinical predictive factors determining the benefits of curative resection for synchronous metastases were identified.

\section{Materials and methods}

Patient characteristics. A total of 103 patients who were diagnosed with stage IV CRC with liver and/or lung metastases 
at the Osaka Medical Center for Cancer and Cardiovascular Diseases between 1983 and 2010 were investigated (Table I). All the patients had histologically confirmed CRC with distant metastasis and underwent curative resection for the primary and metastatic lesions. The surgical specimens were fixed in formalin, processed through graded ethanols and embedded in paraffin blocks. The histological sections were stained with hematoxylin and eosin and elastica-van Gieson's stain and the degree of histological differentiation, lymphatic invasion and venous invasion were assessed. Data on patient age and gender, primary tumour site (rectum or colon), distant metastatic site (liver and/or lung), pathological stage (histological grade, tumour invasiveness, lymph node metastases, lymphatic invasion and venous invasion) and perioperative chemotherapy were retrieved from patient medical records and retrospectively evaluated.

Preoperative evaluation. Preoperatively, the extent of tumour spread was determined by using modalities such as X-ray, computed tomography (CT), magnetic resonance imaging and/or positron emission tomography (PET). The intraoperative findings contributed to the determination of metastatic tumour spread. Following surgery, all the patients underwent follow-up blood tests measuring the serum carcinoembryonic antigen (CEA) levels and imaging examinations, such as abdominal ultrasonography, CT, chest X-ray and/or PET every 3-6 months. In this study, the time-to-recurrence after the first synchronous curative resection for primary and metastatic lesions was also evaluated during the postoperative follow-up and is referred to as 'recurrence interval'.

Adjuvant therapy. Postoperatively, a proportion of the patients received chemotherapy following provision of written informed consent. The adjuvant therapies were administered according to the the guidelines of the Japanese Society for Cancer of the Colon and Rectum (8) and included mFOLFOX6 (oxaliplatin $85 \mathrm{mg} / \mathrm{m}^{2}$ and 5-fluorouracil 2,800 $\mathrm{mg} / \mathrm{m}^{2}$ per 2 weeks x 12 courses), tegafur + uracil (UFT; $300 \mathrm{mg} / \mathrm{m}^{2} /$ day x 28 days per 5 weeks x 5 courses), capecitabine $\left(2,500 \mathrm{mg} / \mathrm{m}^{2} /\right.$ day x 14 days per 3 weeks $\times 8$ courses $)$, or S-1 ( $80 \mathrm{mg} / \mathrm{m}^{2} /$ day x 28 days per 6 weeks x 4 courses). The clinicopathological factors were assessed according to the tumour node metastasis (TNM) classification of the International Union Against Cancer (9).

Statistical analysis. Data were analyzed with the Pearson's Chi-square test or the Fisher's exact test. The Mann-Whitney $\mathrm{U}$ test was used for comparison between different groups. Kaplan-Meier survival curves were plotted and compared with the generalized log-rank test. Univariate and multivariate analyses were performed using a Cox regression model for overall survival (OS) and disease-free survival (DFS) following final curative resection, to identify independent factors. Two-sided P-values of $<0.05$ were considered to indicate statistically significant differences. All the tests were analyzed using JMP software, version 11.0 (SAS Institute, Cary, NC, USA).

This study was designed in accordance with the Institutional Ethical Guidelines and received approval from the Ethics Committee of the Osaka Medical Center for Cancer and Cardiovascular Diseases.
Table I. Clinicopathological factors in metastatic colorectal cancer patients $(n=103)$.

\begin{tabular}{|c|c|}
\hline Factors & Patient no. (\%) \\
\hline Age, years (range) & $61(20-81)$ \\
\hline \multicolumn{2}{|l|}{ Gender } \\
\hline Male & $61(59.2)$ \\
\hline Female & $42(40.8)$ \\
\hline \multicolumn{2}{|l|}{ Primary tumour location } \\
\hline Rectum & $36(35.0)$ \\
\hline Rectosigmoid & 7 \\
\hline Upper rectum & 17 \\
\hline Lower rectum & 11 \\
\hline Anal region & 1 \\
\hline Colon & $67(65.0)$ \\
\hline Cecum & 6 \\
\hline Ascending & 15 \\
\hline Transverse & 8 \\
\hline Descending & 4 \\
\hline Sigmoid & 33 \\
\hline N/A & 1 \\
\hline \multicolumn{2}{|l|}{ Histological grade } \\
\hline Well differentiated Ad & $27(26.2)$ \\
\hline Moderately differentiated Ad & $70(67.9)$ \\
\hline Others $^{\mathrm{a}}$ & $4(3.9)$ \\
\hline N/A & $2(2.0)$ \\
\hline \multicolumn{2}{|l|}{ Tumour invasion } \\
\hline $\mathrm{T} 3$ & $67(65.0)$ \\
\hline $\mathrm{T} 4 \mathrm{a}$ & $27(26.2)$ \\
\hline $\mathrm{T} 4 \mathrm{~b}$ & $5(4.8)$ \\
\hline $\mathrm{N} / \mathrm{A}$ & $4(4.0)$ \\
\hline \multicolumn{2}{|l|}{ Lymph node metastasis } \\
\hline No & $31(30.1)$ \\
\hline N1 & $34(33.0)$ \\
\hline $\mathrm{N} 2 \mathrm{a}$ & $27(26.2)$ \\
\hline $\mathrm{N} 2 \mathrm{~b}$ & $9(8.8)$ \\
\hline $\mathrm{N} / \mathrm{A}$ & $2(1.9)$ \\
\hline \multicolumn{2}{|l|}{ Lymphatic invasion } \\
\hline Absent & $87(84.5)$ \\
\hline Present & $11(10.7)$ \\
\hline $\mathrm{N} / \mathrm{A}$ & $5(4.8)$ \\
\hline \multicolumn{2}{|l|}{ Venous invasion } \\
\hline Absent & $89(86.4)$ \\
\hline Present & $9(8.8)$ \\
\hline $\mathrm{N} / \mathrm{A}$ & $5(4.8)$ \\
\hline \multicolumn{2}{|l|}{ Metastases } \\
\hline \multicolumn{2}{|l|}{ Liver $(n=90)$} \\
\hline Solitary & $42(40.7)$ \\
\hline$\geq 2$ & $48(46.6)$ \\
\hline \multicolumn{2}{|l|}{ Lung $(n=20)$} \\
\hline Solitary & $12(11.6)$ \\
\hline$\geq 2$ & $8(7.8)$ \\
\hline Synchronous liver and lung $(n=7)$ & \\
\hline
\end{tabular}

aPoorly differentiated adenocarcinoma, mucinous adenocarcinoma, or squamous cell carcinoma. Ad, adenocarcinoma N/A, not available. 
Table II. Clinical results of liver and/or lung metastases in colorectal cancer (CRC) patients $(\mathrm{n}=103)$.

\begin{tabular}{lccc}
\hline Factors & $\begin{array}{c}\text { Liver, no. }(\%) \\
(\mathrm{n}=83)\end{array}$ & $\begin{array}{c}\text { Lung, no. }(\%) \\
(\mathrm{n}=13)\end{array}$ & $\begin{array}{c}\text { Liver and lung, } \\
\text { no. }(\%)(\mathrm{n}=7)\end{array}$ \\
\hline CEA $(\mathrm{ng} / \mathrm{ml})$ & $17.4(1.0-2,540.0)$ & $3.4(1.0-20.0)$ & $3.5(2.4-4.0)$ \\
Primary CRC location & & & $2(28.6)$ \\
Rectum & $27(32.5)$ & $8(61.5)$ & $5(71.4)$ \\
Colon & $56(67.5)$ & $5(38.5)$ & 0.304 \\
Recurrence following & & & $0(0.0)$ \\
curative resection & $17(20.4)$ & $8(61.5)$ & $7(100.0)$ \\
None & $47(56.6)$ & $1(7.7)$ & $7(100.0)$ \\
Liver & $32(38.6)$ & $3(23.1)$ & $2(28.6)$ \\
Lung & $11(13.2)$ & $0(0.0)$ & $2(28.6)$ \\
Bones & $3(3.6)$ & $0(0.0)$ & $4(57.1)$ \\
Brain & $10(12.0)$ & $2(15.4)$ & $1(14.2)$ \\
Nistant lymph nodes & $5(6.0)$ & $1(7.7)$ & N/A \\
Others ${ }^{b}$ & & N/A \\
\hline
\end{tabular}

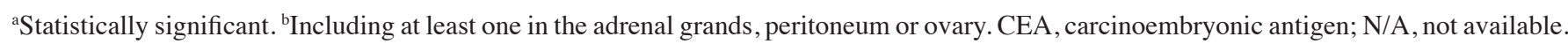

\section{Results}

Patient characteristics. The patient characteristics are summarized in Table I. The median patient age was 61 years (range, 20-81 years) and 61 patients (59.2\%) were male. The primary tumours were located in the rectum (36 patients, $35.0 \%$ ), or the colon (67 patients, $65.0 \%$ ). The most common site of metastases at presentation was the liver (90 patients, $87.3 \%$ ), followed by the lung (20 patients, $19.4 \%$ ). The median number of liver or lung metastatic sites was 2 (range, 1-7) and 1 (range, 1-3), respectively.

Survival analysis. The median OS in the entire study population was 4.60 years. The cohort of 103 patients underwent curative resection of primary and metastatic lesions. Curative resection of the liver or lung was performed in 90 and 20 patients, respectively, whereas liver and lung resections were concurrently performed in 7 patients. The median OS was 20.7 months in this population (Fig. 1). Following curative resection, 25 patients $(24.2 \%)$ had no recurrence [median DFS, 5.69 years (range, 1.20-21.73 years)], whereas 14 patients $(13.5 \%)$ received more than one re-resection for disease recurrence and survived without any further recurrence thereafter [median DFS, 5.53 years (range, 2.30-11.89 years)]. The DFS curves of liver, lung and synchronous liver and lung metastatic CRC are plotted in Fig. 2.

Treatment outcome. Following curative resection, the patients exhibited several recurrences such as in the liver, lung, bone, brain and distant lymph nodes (Table II). In cases with liver or lung metastatic $\mathrm{CRC}, 17$ and 8 patients, respectively, underwent curative resection of primary and metastatic lesions without any recurrence. However, in cases with synchronous liver and lung metastatic CRC, all the patients developed re-recurrence following curative resection and the median DFS of this population was 5.46 months.

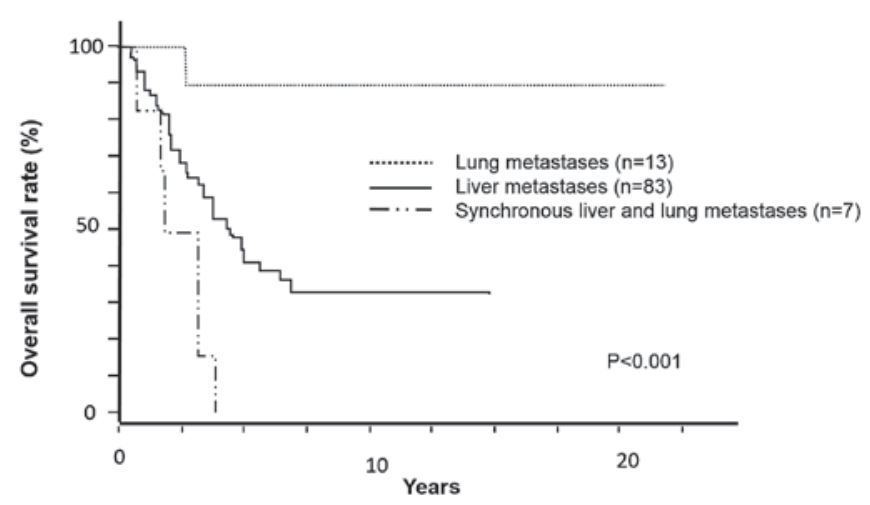

Figure 1. Overall survival curves based on metastatic lesions in colorectal cancer (CRC) patients following curative surgery. The postoperative overall survival rate was significantly lower in CRC patients with synchronous liver and lung metastases $(\mathrm{P}<0.001, \log$-rank test $)$.

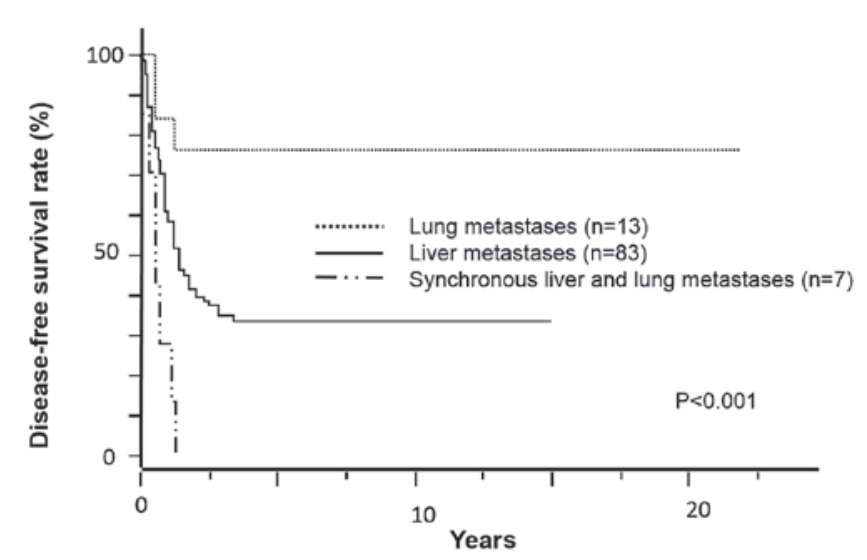

Figure 2. Disease-free survival curves based on metastatic lesions in patients with colorectal cancer (CRC) following curative surgery. The postoperative disease-free survival rate was found to be significantly lower in CRC patients with synchronous liver and lung metastases $(\mathrm{P}<0.001$, log-rank test). 
Table III. Univariate analysis for overall survival with chemotherapy following curative resection (Cox proportional hazards regression model).

\begin{tabular}{lccc}
\hline & \multicolumn{3}{c}{ Univariate analysis } \\
\cline { 2 - 4 } Chemotherapy & HR & $95 \%$ CI & 0.919 \\
\hline Oxaliplatin & 0.96 & $0.47-1.89$ & 0.066 \\
Irinotecan & 1.92 & $0.95-3.68$ & 0.783 \\
5-FU-based & 0.91 & $0.50-1.78$ & 0.446 \\
Bevacizumab & 0.65 & $0.15-1.78$ & P-value \\
\hline
\end{tabular}

Includes 5-FU, capecitabine, UFT, or S-1. HR, hazard ratio; CI, confidence interval; 5-FU, 5-fluorouracil.

Table IV. Univariate and multivariate analyses of factors associated with DFS (Cox proportional hazards regression model).

\begin{tabular}{|c|c|c|c|c|c|c|}
\hline \multirow[b]{2}{*}{ Factors } & \multicolumn{3}{|c|}{ Univariate analysis } & \multicolumn{3}{|c|}{ Multivariate analysis } \\
\hline & HR & $95 \% \mathrm{CI}$ & P-value & HR & $95 \% \mathrm{CI}$ & P-value \\
\hline $\begin{array}{l}\text { Age, years } \\
(<61 \text { vs. } \geq 62)\end{array}$ & 1.18 & $0.72-1.93$ & 0.502 & & & \\
\hline $\begin{array}{l}\text { Gender } \\
\text { (Male vs. female) }\end{array}$ & 1.09 & $0.66-1.82$ & 0.727 & & & \\
\hline $\begin{array}{l}\text { Primary CRC location } \\
\text { (Lower rectum and anus vs. others) }\end{array}$ & 1.66 & $0.79-3.13$ & 0.163 & & & \\
\hline $\begin{array}{l}\text { Histological grade } \\
\left(\text { Well-mod }^{\mathrm{b}} \text { vs. others }{ }^{\mathrm{c}}\right)\end{array}$ & 3.95 & $0.94-11.10$ & 0.057 & & & \\
\hline $\begin{array}{l}\text { CEA, ng/ml } \\
(\geq 5 \text { vs. }<5)\end{array}$ & 0.98 & $0.58-1.70$ & 0.951 & & & \\
\hline $\begin{array}{l}\text { Tumour invasion } \\
\text { (T4a-b vs. T3) }\end{array}$ & 1.70 & $1.01-2.81$ & 0.045 & 2.20 & $1.27-3.78$ & $0.005^{\mathrm{a}}$ \\
\hline $\begin{array}{l}\text { Lymph node metastasis } \\
\text { (N1-2 vs. N0) }\end{array}$ & 1.39 & $0.81-2.49$ & 0.232 & & & \\
\hline $\begin{array}{l}\text { Lymphatic invasion } \\
\text { (Present vs. absent) }\end{array}$ & 0.62 & $0.32-1.36$ & 0.224 & & & \\
\hline $\begin{array}{l}\text { Venous invasion } \\
\text { (Present vs. absent) }\end{array}$ & 1.18 & $0.55-3.08$ & 0.682 & & & \\
\hline $\begin{array}{l}\text { Metastases } \\
\text { (Liver or lung vs. synchronous) }\end{array}$ & 4.11 & $1.67-8.70$ & $0.003^{\mathrm{a}}$ & 3.69 & $1.44-8.33$ & $0.008^{\mathrm{a}}$ \\
\hline $\begin{array}{l}\text { Recurrence interval } \\
\text { after the first operation }^{\mathrm{d}} \\
\text { (<1 year vs. } \geq 1 \text { year) }\end{array}$ & 6.09 & $3.51-11.06$ & $<0.001^{\mathrm{a}}$ & 5.65 & $3.20-10.41$ & $<0.001^{\mathrm{a}}$ \\
\hline
\end{tabular}

a Statistically significant. ${ }^{\mathrm{b}}$ Well and moderately differentiated adenocarcinoma. ${ }^{\mathrm{c}}$ Poorly differentiated, mucinous adenocarcinoma, or squamous cell carcinoma. ${ }^{\mathrm{d}}$ First curative resection of primary and metastatic lesions. DFS, disease-free survival; HR, hazard ratio; CI, confidence interval; CRC, colorectal cancer; CEA, carcinoembronic antigen.

Chemotherapy. Of the 103 patients, 81 (78.6\%) received adjuvant chemotherapy following curative resection. Oxaliplatin and irinotecan were used in 22 (27.1\%) and 15 patients $(18.5 \%)$, respectively. 5-FU, capecitabine or UFT were administered to 77 patients $(74.7 \%)$. Finally, 8 patients $(7.7 \%)$ received bevacizumab. In our study, the selection of chemotherapy was not found to be significantly associated with patient outcome (Table III).

Factors associated with DFS. The univariate and multivariate analyses of factors associated with DFS are presented in Table IV. In the univariate analysis, tumour invasion [hazard 
Table V. Univariate and multivariate analyses of factors associated with OS (Cox proportional hazards regression model).

\begin{tabular}{|c|c|c|c|c|c|c|}
\hline \multirow[b]{2}{*}{ Factors } & \multicolumn{3}{|c|}{ Univariate analysis } & \multicolumn{3}{|c|}{ Multivariate analysis } \\
\hline & HR & $95 \% \mathrm{CI}$ & P-value & HR & $95 \% \mathrm{CI}$ & P-value \\
\hline $\begin{array}{l}\text { Age, years } \\
(<61 \text { vs. } \geq 62)\end{array}$ & 1.10 & $0.64-1.90$ & 0.707 & & & \\
\hline $\begin{array}{l}\text { Gender } \\
\text { (Male vs. female) }\end{array}$ & 1.42 & $0.81-2.56$ & 0.217 & & & \\
\hline $\begin{array}{l}\text { Primary CRC location } \\
\text { (Lower rectum and anus vs. others) }\end{array}$ & 3.09 & $1.44-6.03$ & $0.005^{\mathrm{a}}$ & 4.45 & $1.91-9.54$ & $0.001^{\mathrm{a}}$ \\
\hline $\begin{array}{l}\text { Histological grade } \\
\left(\text { Well-mod }^{\mathrm{b}} \text { vs. others }{ }^{\mathrm{c}}\right)\end{array}$ & 3.18 & $0.77-8.62$ & 0.097 & & & \\
\hline $\begin{array}{l}\text { CEA, ng/ml } \\
(\geq 5 \text { vs. }<5)\end{array}$ & 1.38 & $0.90-2.15$ & 0.132 & & & \\
\hline $\begin{array}{l}\text { Tumour invasion } \\
\text { (T4a-b vs. T3) }\end{array}$ & 1.56 & $1.01-2.38$ & $0.045^{\mathrm{a}}$ & 5.99 & $3.06-12.34$ & $<0.001^{\mathrm{a}}$ \\
\hline $\begin{array}{l}\text { Lymph node metastasis } \\
\text { (N1-2 vs. N0) }\end{array}$ & 1.09 & $0.68-1.61$ & 0.860 & & & \\
\hline $\begin{array}{l}\text { Lymphatic invasion } \\
\text { (Present vs. absent) }\end{array}$ & 0.66 & $0.36-1.32$ & 0.231 & & & \\
\hline $\begin{array}{l}\text { Venous invasion } \\
\text { (Present vs. absent) }\end{array}$ & 1.18 & $0.62-2.54$ & 0.623 & & & \\
\hline $\begin{array}{l}\text { Metastases } \\
\text { (Liver or lung vs. synchronous) }\end{array}$ & 2.99 & $1.23-6.18$ & $0.018^{\mathrm{a}}$ & 4.03 & $1.44-9.77$ & $0.010^{\mathrm{a}}$ \\
\hline $\begin{array}{l}\text { Recurrence interval } \\
\text { after the first operation }{ }^{\mathrm{d}} \\
(<1 \text { vs. } \geq 1 \text { year })\end{array}$ & 2.69 & $1.78-4.11$ & $<0.001^{\mathrm{a}}$ & 7.95 & $3.97-17.14$ & $<0.001^{\mathrm{a}}$ \\
\hline
\end{tabular}

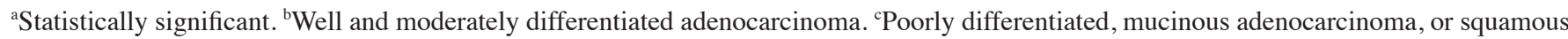
cell carcinoma. ${ }^{d}$ First curative resection of primary and metastatic lesions. HR, hazard ratio; CI, confidence interval; CRC, colorectal cancer; CEA, carcinoembronic antigen.

ratio $(\mathrm{HR})=1.70,95 \%$ confidence interval $(\mathrm{CI}): 1.01-2.81$, $\mathrm{P}=0.045]$, synchronous liver and lung metastases $(\mathrm{HR}=4.11$, $95 \% \mathrm{CI}=1.67-8.70, \mathrm{P}=0.003)$ and recurrence interval after the first curative resection $(\mathrm{HR}=6.09,95 \% \mathrm{CI}: 3.51-11.06, \mathrm{P}<0.001)$ were significantly correlated with DFS. In the multivariate analysis, tumour invasion $(\mathrm{HR}=2.20,95 \% \mathrm{CI}: 1.27-3.78$, $\mathrm{P}=0.005)$, synchronous liver and lung metastases $(\mathrm{HR}=3.69$, 95\% CI: 1.44-8.33, $\mathrm{P}=0.008)$ and recurrence interval after the first curative resection $(\mathrm{HR}=5.65,95 \% \mathrm{CI}: 3.20-10.41, \mathrm{P}<0.001)$ were found to be independent predictors of DFS.

Factors associated with OS. The univariate and multivariate analyses of factors associated with OS are presented in Table V. In the univariate analysis, primary CRC location ( $\mathrm{HR}=3.09,95 \% \mathrm{CI}: 1.44-6.03, \mathrm{P}=0.005)$, tumour invasion $(\mathrm{HR}=1.56,95 \% \mathrm{CI}: 1.01-2.38, \mathrm{P}=0.045)$, synchronous liver and lung metastases ( $\mathrm{HR}=2.99,95 \% \mathrm{CI}: 1.23-6.18, \mathrm{P}=0.018)$ and recurrence interval after the first curative resection $(\mathrm{HR}=2.69$, 95\% CI: 1.78-4.11, P<0.001) were significantly correlated with OS. In the multivariate analysis, primary CRC location ( $\mathrm{HR}=4.45,95 \% \mathrm{CI}$ : 1.91-9.54, $\mathrm{P}=0.001)$, tumour invasion
$(\mathrm{HR}=5.99,95 \% \mathrm{CI}: 3.06-12.34, \mathrm{P}<0.001)$, synchronous liver and lung metastases $(\mathrm{HR}=4.03,95 \% \mathrm{CI}$ : 1.44-9.77, $\mathrm{P}=0.010)$ and recurrence interval after the first curative resection ( $\mathrm{HR}=7.95,95 \% \mathrm{CI}: 3.97-17.14, \mathrm{P}<0.001)$ were found to be independent predictors of OS.

\section{Discussion}

CRC patients with isolated liver or lung metastasis may achieve long-term survival with concurrent curative resection of the primary and metastatic lesions.

It may be useful to determine the necessity of intensive follow-up and selective adjuvant therapy for CRC patients by predicting recurrence and metastases following curative surgical resection $(10,11)$. In the present study, the clinicopathological analysis revealed that $\mathrm{CRC}$ patients with $\mathrm{T} 4 \mathrm{a}-4 \mathrm{~b}$ disease had a poorer prognosis regarding DFS and OS compared to those with T3 disease. Additionally, CRC with synchronous liver and lung metastases was associated with a poorer prognosis compared to CRC with isolated liver or lung metastasis. The data indicated that tumour invasiveness and 
metastatic status (liver and lung) are independent prognostic factors. As regards OS, primary cancer location at the lower rectum and anal region was associated with worse prognosis. It was previously reported that rectal cancer exhibits early recurrence, resulting in poor prognosis (12). Unlike previous studies indicating several prognostic factors, such as lymph node metastasis and vascular invasion, these factors were not found to be prognostically significant, as all the patients in our study had stage IV disease $(13,14)$. In the clinical setting, it must be decided whether re-resection should be selected for recurrence following curative surgical resection for metastatic CRC. In the present study, we also evaluated the recurrence interval during the follow-up period after the first curative surgical resection for metastatic CRC. Our results indicated that a recurrence interval of $<1$ year was associated with a poorer prognosis in terms of DFS and OS after the final curative resection. Of the 103 patients, 54 developed recurrence within 1 year after the first curative resection and 46 of those 54 patients $(85.1 \%)$ were unable to undergo surgical resection for the recurrence. Of the 54 patients, $2(3.7 \%)$ underwent palliative resection for disease recurrence and 7 (12.9\%) underwent curative surgical resection. The remaining 49 patients developed no recurrence within 1 year after the first curative resection. Of those 49 patients, $25(53.0 \%)$ survived without any further recurrence [median DFS, 5.75 years (range, 2.17-21.73 years)], whereas 24 patients developed recurrence and 7 underwent curative surgical resection for the recurrence, surviving without any further recurrence [median DFS, 4.73 years (range, 2.30-11.86 years)]; of the remaining 17 patients, 1 underwent palliative surgical resection and 16 were unable to undergo surgical resection. Our results suggested that combination therapy, namely palliative surgical resection and chemotherapy, may be an option for recurrent cases that appear within 1 year after the first curative resection (3). In CRC therapy, it is essential to prevent metachronous metastasis. Several adjuvant chemotherapies may be beneficial for advanced metastatic CRC $(10,15)$. In such cases, predictive markers of metastasis are crucial, regardless of the traditional TNM classification, and may contribute to the diagnosis and treatment of metachronous distant metastases.

In the present study, the combination of adjuvant chemotherapies did not result in statistically significant differences in patient outcome. This may be due to the fact that the reviewed data were collected over the past 20 years, within which time the strategy of the adjuvant treatment has changed. Adjuvant chemotherapy for CRC has been the treatment of choice in highly suspicious metachronous metastatic cases $(16,17)$. Improving treatments, such as postoperative chemotherapy, combination therapy with chemotherapy following surgical resection, or palliative surgical resection with chemotherapy for metastatic CRC, may contribute to improving patient outcome $(3,10,15-17)$.

In summary, surgical resection may be a potentially curative option for selected CRC patients with liver or lung metastasis. If the metastases are diagnosed as potentially resectable and the patient's performance status is satisfactory, surgical resection of the primary as well as the metastatic lesions may be a viable treatment option. Following surgical resection, tumour invasiveness should be considered. With the combination of surgery and improved chemotherapy, longer-term survival may be achieved.

\section{References}

1. Jemal A, Siegel R, Xu J, et al: Cancer statistics, 2010. CA Cancer J Clin 60: 277-300, 2010.

2. Headrick JR, Miller DL, Nagorney DM, et al: Surgical treatment of hepatic and pulmonary metastases from colon cancer. Ann Thorac Surg 71: 975-979; discussion 979-980, 2001.

3. Park JH, Kim TY, Lee KH, et al: The beneficial effect of palliative resection in metastatic colorectal cancer. Br J Cancer 108: 1425-1431, 2013.

4. Kanzaki R, Higashiyama M, Oda K, et al: Outcome of surgical resection for recurrent pulmonary metastasis from colorectal carcinoma. Am J Surg 202: 419-426, 2011.

5. Grothey A, Sargent D, Goldberg RM, et al: Survival of patients with advanced colorectal cancer improves with the availability of fluorouracil-leucovorin, irinotecan and oxaliplatin in the course of treatment. J Clin Oncol 22: 1209-1214, 2004.

6. Hurwitz H, Fehrenbacher L, Novotny W, et al: Bevacizumab plus irinotecan, fluorouracil and leucovorin for metastatic colorectal cancer. N Engl J Med 350: 2335-2342, 2004.

7. Sobrero AF, Maurel J, Fehrenbacher L, et al: EPIC: phase III trial of cetuximab plus irinotecan after fluoropyrimidine and oxaliplatin failure in patients with metastatic colorectal cancer. J Clin Oncol 26: 2311-2319, 2008.

8. Watanabe T, Itabashi M, Shimada Y, et al: Japanese Society for Cancer of the Colon and Rectum (JSCCR) guidelines 2010 for the treatment of colorectal cancer. Int J Clin Oncol 17: 1-29, 2012.

9. Sobin LH and Fleming ID: TNM Classification of Malignant Tumors. 7th edition. Union Internationale Contre le Cancer and the American Joint Committee on Cancer. Wiley-Blackwell, Oxford, UK, pp100-109, 2009.

10. Bathe OF, Dowden S, Sutherland F, et al: Phase II study of neoadjuvant 5-FU + leucovorin + CPT-11 in patients with resectable liver metastases from colorectal adenocarcinoma. BMC Cancer 4: 32, 2004.

11. Kornmann M, Formentini A, Ette C, et al: Prognostic factors influencing the survival of patients with colon cancer receiving adjuvant 5-FU treatment. Eur J Surg Oncol 34: 1316-1321, 2008.

12. Lan YT, Chang SC, Yang SH, et al: Comparison of clinicopathological characteristics and prognosis between early and late recurrence after curative surgery for colorectal cancer. Am J Surg 207: 922-930, 2014.

13. Derkinderen DJ, Boxma OJ, Koten JW, et al: Stochastic theory of oncogenesis. Anticancer Res 10: 497-504, 1990.

14. Miyoshi N, Ishii H, Mimori K, et al: Abnormal expression of TRIB3 in colorectal cancer: a novel marker for prognosis. Br J Cancer 101: 1664-1670, 2009.

15. Koshariya M,JagadRB,Kawamoto J,et al: An update and ourexperience with metastatic liver disease. Hepatogastroenterology 54: 2232-2339, 2007.

16. Schwartzberg LS, Rivera F, Karthaus M, et al: PEAK: A randomized, multicenter phase II study of panitumumab plus modified fluorouracil, leucovorin and oxaliplatin (mFOLFOX6) or bevacizumab plus mFOLFOX6 in patients with previously untreated, unresectable, wild-type KRAS exon 2 metastatic colorectal cancer. J Clin Oncol 32: 2240-2247, 2014.

17. Price TJ, Peeters M, Kim TW, et al: Panitumumab versus cetuximab in patients with chemotherapy-refractory wild-type KRAS exon 2 metastatic colorectal cancer (ASPECCT): a randomised, multicentre, open-label, non-inferiority phase 3 study. Lancet Oncol 15: 569-579, 2014. 